\title{
Agnathia-otocephaly: prenatal diagnosis by two- and three-dimensional ultrasound and magnetic resonance imaging. Case report.
}

\author{
Wagner Jou Hisaba, Hérbene José Figuinha Milani, Edward Araujo Júnior, Jurandir Piassi \\ Passos, Enoch Quinderé Sá Barreto, Natália Silva Carvalho, Talita Micheletti Helfer, David \\ Batista Silva Pares, Luciano Marcondes Machado Nardozza, Antonio Fernandes Moron
}

Department of Obstetrics, Paulista School of Medicine, Federal University of São Paulo (EPM-UNIFESP), São

Paulo-SP, Brazil

\begin{abstract}
A case of prenatally diagnosed otocephaly is reported. Otocephaly is an extremely rare malformation characterized by absence or hypoplasia of the mandible and abnormal horizontal position of the ears. 2D ultrasound performed at 25 weeks of gestation revealed agnathia, proboscis and hypotelorism. 3D ultrasound (rendering mode) and magnetic resonance imaging were used to evaluate the facial features, and were essential for characterization of facial malformations in otocephaly and for the demonstration and correct prenatal counseling of the couple.
\end{abstract}

Keywords: otocephlay, prenatal diagnosis, 2D ultrasound, 3D ultrasound, magnetic resonance imaging.

\section{Introduction}

Agnathia-otocephaly is a rare malformation complex of the first pharyngeal arch occurring during facial development between the fourth and eighth weeks of gestation [1]. Since its first description by Kerckring in 1717, more than 100 affected individuals have been reported. It has been reported to occur in fewer than 1 in 70000 births $[2,3]$. The defining characteristics of this malformation sequence are the absence of the mandible (agnathia) or severe mandibular hypoplasia, microstomia, absence or underdevelopment of the tongue, and midfacial location of the ears in the form of auricular malposition called melotia, and/or auricular fusion called synotia [3]. This malformation can also present in association with diverse anomalies including holoprosencephaly, skeletal, genito-

Received 24.04.2014 Accepted 21.05.2014

Med Ultrason

2014, Vol. 16, No 4, 377-379

Corresponding author: Prof. Edward Araujo Júnior, PhD

Department of Obstetrics, Paulista School

of Medicine - Federal University of São Paulo (EPM-UNIFESP)

Rua Carlos Weber, 956, apto. 113 Visage

Vila Leopoldina, São Paulo - SP, Brazil

CEP 05303-000

Phone / Fax: +55-11-37965944

Email: araujojred@terra.com.br urinary, cardiovascular anomalies, and situs inversus [3]. The etiology is unknown with potential genetic and teratogenic causes proposed. More recently, agnathia-otocephaly was shown to be caused by new heterozygous or biallelic mutations in PRRX1 gene in two unrelated babies [4-6].

We present a case of agnathia-otocephaly diagnosed in the second trimester of pregnancy by $2 \mathrm{D}$ and $3 \mathrm{D}$ ultrasound and magnetic resonance imaging (MRI).

\section{Case report}

A 32-year-old pregnant woman, gravida 3, para 2, with no family history of congenital anomalies or consanguinity was evaluated in our hospital. She had two cesarean delivered. There was not any drug exposure or significant illness. She had a previous ultrasound scan at 12 weeks of gestation which had been reported as normal. She was referred to our hospital because of abnormal findings on ultrasound scan at 22 weeks in a primary medical center: proboscis, hypotelorism, associated to a polydramnios. At 25 weeks, at our hospital, the 2D ultrasound scan of the fetal head showed the presence of a proboscis, hypotelorism and agnathia (fig 1a). The amniotic fluid index was $23 \mathrm{~cm}$. The cerebral was normal without signs of holoprosencephaly. By using the 3D ultrasound in the 


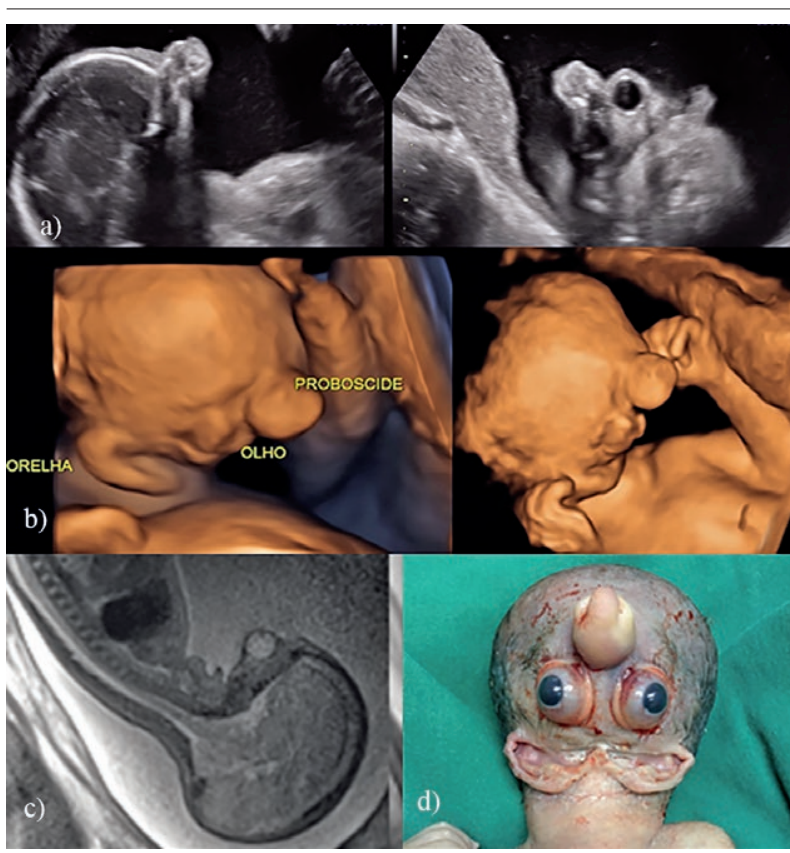

Fig 1. a) 2D ultrasound showing agnathia, proboscis and hypotelorism; b) 3D ultrasound showing agnathia, proboscis and good visualization of the low set ears (in the neck) with auricular fusion; c) MRI T2 sagittal view showing agnathia and proboscis; d) Frontal view of the newborn showing agnathia, proboscis, hypotelorism, absence of mouth, and abnormal position of the ears.

rendering mode (Voluson E8 series, with 4-8-MHz transducer and 4DView 10.0 Software, GE-Medical Systems, Zipf, Austria) there was a good visualization of the low set ears (in the neck) with auricular fusion or anotia (fig 1b). Cordocentesis showed a normal karyotype (46 XX). The fetal echocardiography showed double-outlet right ventricle, atrio-ventricular septal defect, aortic hypoplasia, common atrium and single atrio-ventricular valve regurgitation. MRI was performed on $1.5 \mathrm{~T}$ scanner, and the imaging findings of the fetal face and brain were the same those seen on ultrasound scan (fig 1c). No abnormalities were found in abdomen or thorax. Interruption of the pregnancy is not allowed by Brazilian laws, except in the high risks of maternal death. There was an increased amniotic fluid and an amniodrenage was done at 27 weeks. After a second amniodrenage in the $29^{\text {th }}$ weeks of gestation, uterine contractions appeared and the medical team together with the parents decided to the deliver in face of the maternal risks of the polyhydramnios and the poor fetal prognosis. Delivery occurred at 29 weeks by cesarean section (two previous cesarean scars). Ex utero intrapartum treatment (EXIT) procedure was not performed in according to the opinion of the parents. A female newborn with $935 \mathrm{~g}$ was delivered but there was not the characterization of the oropharyngeal airway (fig 1d). Death occurred spontaneously after few minutes of the birth.

\section{Discussion}

Otocephaly or agnathia-synotia-microstomia syndrome is a very rare congenital and facial complex characterized by the most severe form of first branchial arch malformation [7]. Embryologically, this lethal malformation is thought to be result of failure of mandibular development, possibly secondary to a defect in neural crest cell migration [8]. Facial development of the human embryo occurs mainly between the fourth and eighth weeks of post conception. The mandible is the first part of the face to form. It arises from the fusion of the medial ends of two mandibles prominences that inferiorly delimit the stomoderm [9]. The primary malformation in otocephaly is mandibular aplasia (agnathia) associated with ventromedial displacement of the external ears structures (synotia), absence of the tongue (aglossia), oral aperture as a minute opening 2-3 $\mathrm{mm}$ in diameter (microstomia), and persistence of the buccopharyngeal membrane. These features are probably secondary effects of aplasia of the mandibular archs [10].

Otocephaly can be found isolated or associated with anomalies such as holoprosencephaly, neural tube defects, cephalocele, midline proboscis, tracheoesophageal fistula, cardiac anomalies, adrenal hypoplasia, genitourinary and renal malformations, and skeletal anomalies [11]. Polyhydramnios is frequently reported. The actual incidence of otocephaly is unknown, but it is estimated to be one in 70000 infants [3]. Most cases are sporadic, but some drugs such as theophylline, beclomethasone, and salicylates are reported as associated substances [12]. In general, nearby all infants with otocephaly do not survive long after birth. Only a few cases with milder forms of malformations were reported to have long-term survival [13].

The diagnosis of otocephaly has traditionally been made by subjective assessment of $2 \mathrm{D}$ ultrasound. In the mild form of the disease or with an inexperienced sonographer, the definite diagnosis could be difficult. 3D ultrasound easily offers several advantages in prenatal diagnosis of facial abnormalities, and facilities, in complex facial malformations, appreciation of the nature and extent of the abnormality [14].

In this case reported the diagnosis of otocephaly was made with 25 weeks of gestation, after previous studies had suspected of facial malformation. In addition to the features of facial malformations in otocephly, proboscis and cardiac abnormalities were observed too. We did not observe changes in brain morphology. The polyhydram- 
nios was present in markedly, being one of the factors that contributed to the decision of the anticipation of pregnancy (maternal risk), since that Brazilian laws do not allow termination of pregnancy.

The use of 3D ultrasound was essential for characterization of facial malformations and for the demonstration and correct prenatal counseling of the couple. As is routine in the Fetal Neurology Division of the Paulista School of Medicine - Federal University of São Paulo, MRI was performed, and in the same way that the 3D ultrasound, contributed for the characterization of the facial malformations.

\section{References}

1. Gekas J, Li B, Kamnasaran D. Current perspectives on the etiology of agnathia-otocephaly. Eur J Med Genet 2010; 53: 358-366.

2. Faye-Petersen O, David E, Rangwala N, Seaman JP, Hua Z, Heller DS. Otocephaly: report of five new cases and a literature review. Fetal Pediatr Pathol 2006; 25: 277-296.

3. Schiffer C, Tariverdian G, Schiesser M, Thomas MC, Sergi C. Agnathia-otocephaly complex: report of three cases with involvement of two different Carnegie stages. Am J Med Genet 2002; 112: 203-208.

4. Sergi C, Kamnasaran D. PRRX1 is mutated in a fetus with agnathia- otocephaly. Clin Genet 2011; 79: 293-295.
5. Çelik T, Simsek PO, Sozen T, et al. PRRX1 is mutated in an otocephalic newborn infant conceived by consanguineous parents. Clin Genet 2012; 81: 294-297.

6. Dasouki M, Andrews B, Parimi P, Kamnasaran D. Recurrent agnathia-otocephaly caused by DNA replication slippage in PRRX1. Am J Med Genet A 2013; 161A: 803-808.

7. Ducarme G, Largilliere C, Amarenço B, et al. Three-dimensional ultrasound in prenatal diagnosis of isolated otocephaly. Prenat Diagn 2007; 27: 481-483.

8. Johnston MC, Sulik KK. Some abnormal patterns of development in the craniofacial region. Birth Defects Orig Artic Ser 1979; 15: 23-42.

9. Moore K. The Developing Human. Philadelphia, PA, WB, Saunders, 1982

10. Black FO, Myers EN, Rorke LB. Aplasia of the first and second branchial arches. Arch Otolaryngol 1973; 98: 124128 .

11. O'Neill BM, Alessi AS, Petti NA. Otocephaly or agnathiasynotia-microstomia syndrome: report of a case. J Oral Maxillofac Surg 2003; 61: 834-837.

12. Ibba RM, Zoppi MA, Floris M, et al. Otocephaly: prenatal diagnosis of a new case and etiopathogenetic considerations. Am J Med Genet 2000; 90: 427-429.

13. Erlich MS, Cunninghan ML, Hudgins L. Transmission of the dysgnathia complex from mother to daughter. Am J Med Genet 2000; 95: 269-274.

14. Rotten D, Levaillant JM. Two- and three-dimensional sonographic assessment of the fetal face. A systematic analysis of the normal face. Ultrasound Obstet Gynecol 2004; 23: $224-231$. 